\title{
Effect of Intrathecal Methotrexate Injection on Neurocognitive Functions in Children with Non Hodgkin Lymphoma after Treatment
}

\author{
Somaya El-Sayed Hadhoud MD ${ }^{1}$, Ahlam Abdel Salam Nabieh El-Adawy MD², Abeer \\ Abd Elmonem Ahmed MD ${ }^{1}$, Mona Abo-Alkasem Mahmoud MS ${ }^{1}$ \\ ${ }^{1}$ Pediatric Department, Sohag University Hospital, Sohag University, Sohag, Egypt \\ ${ }^{2}$ Phoniatrics, ENT Department, Sohag University, Sohag, Egypt
}

\begin{abstract}
Introduction and aim of work: Neurocognitive late effects are common sequelae of cancer in children, especially in those who have undergone treatment for brain tumors or in those receiving prophylactic cranial radiation or intrathecal chemotherapy therapy to treat leukemia and non Hodgkin lymphoma (NHL). As NHL represents 8-10\% of all malignancies in children between 5-19 years of age (Cairo, 2009) and all NHL children receive intrathecal methotrexate as therapy or prophylaxis so we studied effect of intrathecal methotrexate in NHL treated children in their cognitive function and compare it with normal children, also we studied effect of some risk factors (age at disease onset and number of intrathecal injections) on the affected intelligence subscales and lastly a suitable and applicable model to evaluate neurocognitive function was done.

Patients and methods: The study included 25 NHL treated children and $\mathbf{1 0}$ children as controls, all children are subjected to some specific neurocognitive tests and sheet for assessment of neurocognitive function as complementary study.

Result: It showed that total IQ score, verbal and quantitative subscales are significantly affected in NHL patients and verbal subscale is more affected in children who began treatment at younger age.
\end{abstract}

\section{Introduction}

Cognition is the set of all mental abilities and processes related

to knowledge: attention, memory \& workin g memory, judgement\&evaluation, reasoning \& "computation", problem solving \& decision making, comprehension \& production of language, (Anderson and John, 2004). Non-Hodgkin lymphoma (NHL) results from malignant proliferation of cells of lymphocytic lineage. Although malignant lymphomas are generally restricted to lymphoid tissue such as lymph nodes, Peyer's patches and spleen, it is not uncommon to find bone marrow involvement in children. Bone and primary CNS lymphomas are rare presentations (Cairo MS, 2009).
Methotrexate is one of antifolate drugs (Gangjee, 2007). Methotrexate was originally developed and continues to be used for chemotherapy, either alone or in combination with other agents. It is effective for the treatment of a number of cancers including: breast, head and neck, leukemia, lymphoma, lung, osteosarcoma, bladder, and trophoblastic neoplasms (Miller, 2006). Methotrexate can be taken orally or administered by injection (intramuscular, intravenous, subcutaneous, or intrathecal) (Mukherjee, 2010). There are many reports on late neurocognitive deficits after intrathecal chemotherapy (methotrexate) alone, particularly in the domain of executive functions, sequelae seem more severe after high-risk treatment (Buizer et al, 2009). 


\section{Aim of the work}

To evaluate cognitive functions in children treated by intrathecal methotrexate in NHL children and compare it with normal children'evaluate effect of intrathecal methotrexate and its relation to risk factors (age at diseases onset and number of intrathecal injectionsand develop suitable and applicable model to evaluate neurocognitive function

\section{Patients and methods}

This study was cross sectional where we observed cognitive functions using designed cognitive tests after methotrexate therapy that conducted in $\mathbf{3 5}$ children classified into two groups: group(1) 25 NHL treated children, their age ranged from 6-18 years and group (2) 10 healthy children of the same age group and environmental conditions, as a control group,all patients treated at Sohag Cancer Institute and finished treatment course 1 year before study, we excluded Patients with any neurocognitive disability before treatment, who complained of CNS infiltration, who received cranial irradiation or high dose systemic methotrexate and those with hemoglobin less than $8.5 \mathrm{gm} / \mathrm{dL}$.

All children in the study underwent the following protocol which included a sheet for assessment of neurocognitive function(quasi-objective) the sheet included personal, past and family history ,neurological examination and mental status examination and Tests of neurocognitive function (objective tests) which were done after finishing treatment one year or more on cases. The neurocognitive tests which we used (1) Standford Binet $4^{\text {th }}$ edition which assess $\mathbf{4}$ area of intelligence verbal, abstract/visual thinking, quantitative reasoning and short term memory, (2) test of visual perception which measures visual motor organization (mariane frostige; development test) (3) test for short term visual memory and visual perception (Bender Gestalt test) (4) Children's Attention and Adjustment Survey (House Form). Then we studied the significant subscale and its relation to age of cases at time of disease diagnosis and times of intrathecal methotrexate injections.

\section{Results}

Comparison between cases and controls according to Stanford-Binet Intelligence Scale in the study revealed that the verbal and quantitative sub-scales were significantly better among controls compared to cases( $p$ value $\mathbf{. 0 3 7}$ in verbal,. $\mathbf{0 1 8}$ for quantitative) and the abstract/visual and short term memory were better among controls than cases but not significant ( $\mathrm{p}$ value in order 0.411,0.265). The total Stanford-Binet Intelligence Scale was significantly higher among controls compared to cases ( $\mathrm{p}$ value .020). table 1 
SOHAG MEDICAL JOURNAL

Vol. 21 No.1 Jan 2017
Effect of Intrathecal Methotrexate Injection on Neurocognitive Mona Abo-Alkasem Mahmoud

Table 1. Comparison between cases and controls according to Stanford-Binet Intelligence Scale

\begin{tabular}{|l|l|l|l|l|}
\hline \multirow{2}{*}{ Variable } & \multicolumn{2}{|l|}{ Group } & \multirow{2}{*}{} & \multirow{2}{*}{ P test } \\
\cline { 2 - 3 } & Case & Control & value \\
\hline Total score & $\mathbf{8 9 . 6 4} \pm \mathbf{1 4 . 7 0}$ & $\mathbf{1 0 4 . 0 0} \pm \mathbf{1 8 . 0 0}$ & $\mathbf{2 . 4 5 0}$ & $\mathbf{0 . 0 2 0}(\mathbf{S})$ \\
\hline Verbal & $\mathbf{8 4 . 8 8} \pm \mathbf{1 5 . 4 0}$ & $\mathbf{9 7 . 5 0} \pm \mathbf{1 6 . 7 9}$ & $\mathbf{2 . 1 7 5}$ & $\mathbf{0 . 0 3 7}(\mathbf{S})$ \\
\hline Visual/spatial processing & $\mathbf{9 3 . 4 0} \pm \mathbf{1 7 . 3 6}$ & $\mathbf{9 9 . 1 0} \pm \mathbf{2 0 . 5 5}$ & $\mathbf{0 . 8 3 3}$ & $\mathbf{0 . 4 1 1}(\mathbf{N S})$ \\
\hline Quantitative & $\mathbf{8 6 . 6 0} \pm \mathbf{1 6 . 5 5}$ & $\mathbf{1 0 2 . 0 0} \pm \mathbf{1 6 . 7 5}$ & $\mathbf{2 . 4 7 8}$ & $\mathbf{0 . 0 1 8}(\mathbf{S})$ \\
\hline Short term memory & $\mathbf{1 0 5 . 6 8} \pm \mathbf{2 2 . 1 7}$ & $\mathbf{1 1 4 . 7 0} \pm \mathbf{1 8 . 6 0}$ & $\mathbf{1 . 1 3 4}$ & $\mathbf{0 . 2 6 5}(\mathbf{N S})$ \\
\hline
\end{tabular}

Comparison between cases and controls according to other tests (Attention, Bender gestation and Visual perception) did not show any significant difference between cases and controls $\mathrm{p}$ value in order ( $\mathrm{p}$ value $\mathbf{0 . 4 9 6}, \mathrm{p}$ value $\mathbf{0 . 9 8 8}$, and $\mathrm{p}$ value $\mathbf{0 . 1 7 7}$ ). table 2

Table 2. Comparison between cases and controls according to attention, Bender Gestalt and visual perception

\begin{tabular}{|c|c|c|c|c|}
\hline \multirow[t]{2}{*}{ Variable } & \multicolumn{2}{|l|}{ Group } & \multirow[b]{2}{*}{ T test } & \multirow[b]{2}{*}{ P value } \\
\hline & Case & Control & & \\
\hline Attention & $2.27 \pm 1.08$ & $2.00 \pm 0.94$ & 0.688 & 0.496 (NS) \\
\hline Bender gestation & $15.36 \pm 4.81$ & $15.40 \pm 5.59$ & 0.015 & 0.988 (NS) \\
\hline Visual perception & $74.85 \pm 18.87$ & $84.60 \pm 16.47$ & 1.407 & 0.170 (NS) \\
\hline
\end{tabular}

The verbal part of Stanford-Binet Intelligence Scale was better among older aged children in case group and the difference was significant ( $\mathrm{p}$ value $\mathbf{0 . 0 0 7}$ ). table 3

Table 3. Relation between age and verbal subscale of Stanford-Binet Intelligence Scale among cases.

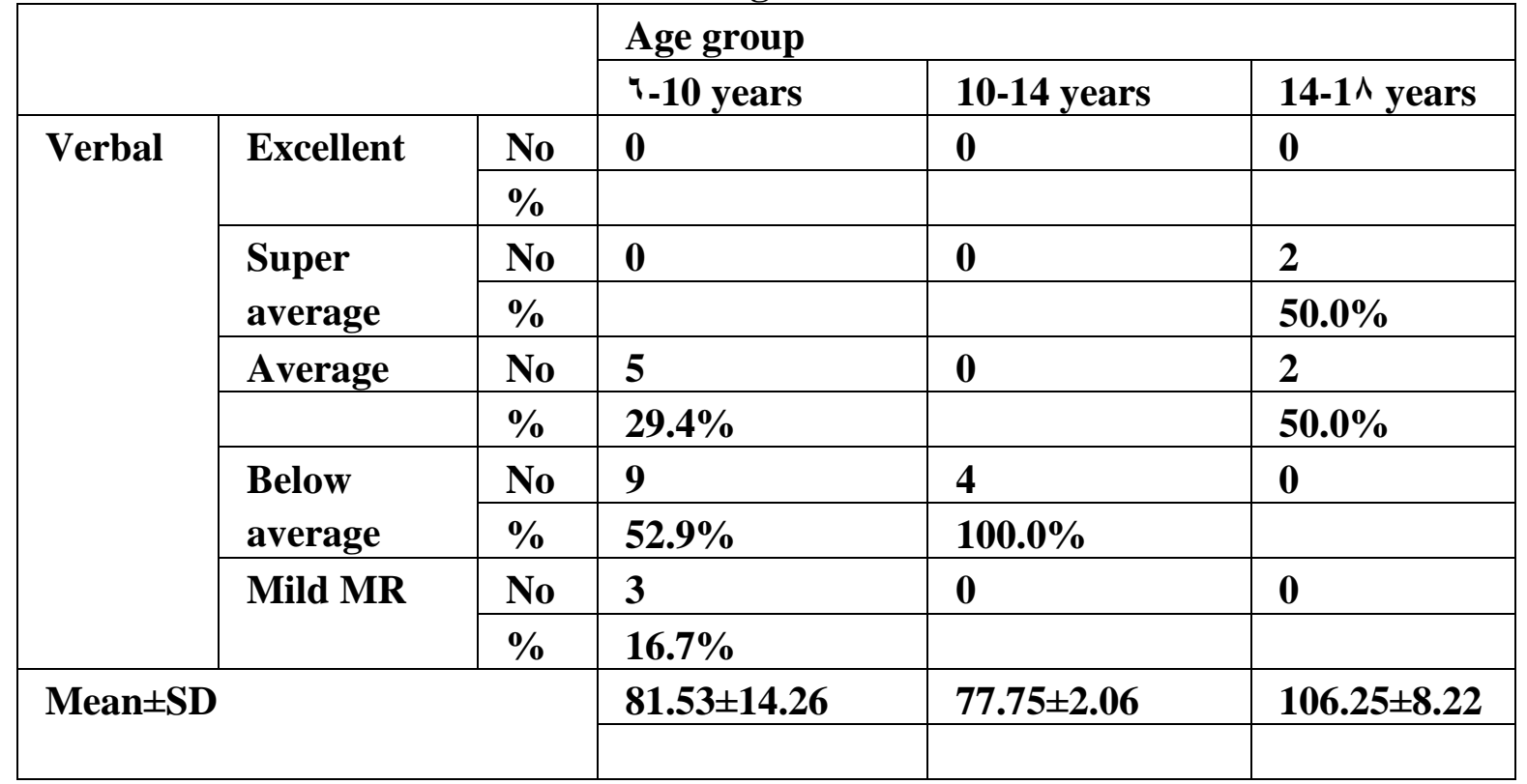

There is no significant difference on effect of age on quantitative subscale between cases (p value 0.086$)$. table 4 
SOHAG MEDICAL JOURNAL

Vol. 21 No.1 Jan 2017
Effect of Intrathecal Methotrexate Injection on Neurocognitive Mona Abo-Alkasem Mahmoud

Table 4. relation between age and quantitative subscale of Stanford-Binet Intelligence Scale variable among cases

\begin{tabular}{|c|c|c|c|c|c|}
\hline & \multicolumn{3}{|l|}{ Age group } \\
\hline & & & 5-10 years & $10-14$ years & 14-19 years \\
\hline \multirow[t]{10}{*}{ Quantitative } & \multirow[t]{2}{*}{ Excellent } & No & 0 & $\mathbf{0}$ & 0 \\
\hline & & $\%$ & & & \\
\hline & \multirow{2}{*}{$\begin{array}{l}\text { Super } \\
\text { average }\end{array}$} & No & 1 & $\mathbf{0}$ & 1 \\
\hline & & $\%$ & $5.9 \%$ & & $25.0 \%$ \\
\hline & Average & No & 8 & $\mathbf{0}$ & 1 \\
\hline & & $\%$ & $47.1 \%$ & & $25.0 \%$ \\
\hline & \multirow{2}{*}{$\begin{array}{l}\text { Below } \\
\text { average }\end{array}$} & No & 5 & 2 & 2 \\
\hline & & $\%$ & $29.4 \%$ & $50.0 \%$ & $50.0 \%$ \\
\hline & \multirow[t]{2}{*}{ Mild MR } & No & 3 & 2 & 0 \\
\hline & & $\%$ & $17.6 \%$ & $50.0 \%$ & \\
\hline \multicolumn{3}{|l|}{ Mean \pm SD } & $80.06 \pm 13.75$ & $82.0 \pm 11.89$ & $96.500 \pm 26.30$ \\
\hline
\end{tabular}

There is no significant influence of times of intrathecal methotrexate injection on neurocognitive functions, we compare with verbal ( $p$ value $\mathbf{0 . 3 6 7}$ ) and quantitative ( $p$ value 0.059). table 5,6

Table (5): Relation between verbal subscale of Stanford-Binet Intelligence Scale and number of intrathecal injections

\begin{tabular}{|c|c|c|c|c|c|}
\hline & \multicolumn{3}{|c|}{ Number of intrathecal injections } \\
\hline & & & 8 & 16 & 24 \\
\hline \multirow[t]{10}{*}{ Verbal } & \multirow[t]{2}{*}{ Excellent } & No & $\mathbf{0}$ & $\mathbf{0}$ & $\mathbf{0}$ \\
\hline & & $\%$ & & & \\
\hline & \multirow{2}{*}{$\begin{array}{l}\text { Super } \\
\text { average }\end{array}$} & No & 1 & $\mathbf{0}$ & 1 \\
\hline & & $\%$ & $10 \%$ & & $50 \%$ \\
\hline & \multirow[t]{2}{*}{ Average } & No & 3 & 4 & $\mathbf{0}$ \\
\hline & & $\%$ & $30 \%$ & $30.8 \%$ & \\
\hline & \multirow{2}{*}{$\begin{array}{l}\text { Below } \\
\text { average }\end{array}$} & No & 5 & 7 & 1 \\
\hline & & $\%$ & $50 \%$ & $53.8 \%$ & $50 \%$ \\
\hline & \multirow[t]{2}{*}{ Mild MR } & No & 1 & 2 & $\mathbf{0}$ \\
\hline & & $\%$ & $10 \%$ & $15.4 \%$ & \\
\hline \multicolumn{3}{|c|}{$\operatorname{Mean} \pm$ SD } & $86 \pm 16.99$ & $82.69 \pm 13.72$ & $93.5 \pm 24.75$ \\
\hline
\end{tabular}


SOHAG MEDICAL JOURNAL

Vol. 21 No.1 Jan 2017
Effect of Intrathecal Methotrexate Injection on Neurocognitive Mona Abo-Alkasem Mahmoud

Table (6): Relation between quantitative subscale of Stanford-Binet Intelligence Scale and number of intrathecal injections

\begin{tabular}{|c|c|c|c|c|c|}
\hline & \multicolumn{3}{|c|}{ Number of intrathecal injections } \\
\hline & & & 8 & 16 & 24 \\
\hline \multirow[t]{10}{*}{ quantitative } & \multirow[t]{2}{*}{ Excellent } & No & $\mathbf{0}$ & $\mathbf{0}$ & $\mathbf{0}$ \\
\hline & & $\%$ & & & \\
\hline & \multirow{2}{*}{$\begin{array}{l}\text { Super } \\
\text { average }\end{array}$} & No & $\mathbf{0}$ & 1 & 1 \\
\hline & & $\%$ & & $7.7 \%$ & $\mathbf{5 0 \%}$ \\
\hline & Average & No & 4 & 5 & $\mathbf{0}$ \\
\hline & & $\%$ & $40 \%$ & $38.5 \%$ & \\
\hline & \multirow{2}{*}{$\begin{array}{l}\text { Below } \\
\text { average }\end{array}$} & No & 2 & 7 & $\mathbf{0}$ \\
\hline & & $\%$ & $20 \%$ & $\mathbf{5 3 . 8 \%}$ & \\
\hline & \multirow[t]{2}{*}{ Mild MR } & No & 4 & $\mathbf{0}$ & 1 \\
\hline & & $\%$ & $40 \%$ & & $50 \%$ \\
\hline \multicolumn{3}{|l|}{$\operatorname{Mean} \pm$ SD } & $81.4 \pm 19.21$ & $90.08 \pm 12.37$ & $90 \pm 31.11$ \\
\hline
\end{tabular}

\section{Discussion}

In a study of adult survivors of childhood non-CNS cancers (ALL-NHL), $\mathbf{1 3 \%}$ to $21 \%$ of survivors reported impairment in task efficiency, organization, memory, or emotional regulation. This rate of impairment was approximately $\mathbf{5 0 \%}$ higher than that reported in the sibling comparison group. Factors such as diagnosis before age 6 years, female gender, cranial radiation therapy, and hearing impediment were associated with more impairment (KadanLottick et al, 2017).

In the present study we choose to study effect of methotrexate drug which given directly intrathecally so it has direct effect on brain and its metabolism as Methotrexate is one of antifolate drugs (Gangjee, 2007). The MTX neurotoxicity (IV and/or intrathecal) can present as acute or chronic. It has a wide clinical spectrum, ranging from sub-clinical manifestations with complete recovery or chronic and progressive leukoencephalopathy (GarciaPuiget al, 2012).

The leukoencephalopathies are divided into hereditary disorders and acquired disorders. The hereditary demyelinating disorders are then classified according to the localization of the underlying metabolic defect (Lyon et al, 2006).

The acquired demyelinating disorders are classified according to their underlying causes into five groups: noninfectiousinflammatory, infectious-inflammatory, toxic-metabolic, hypoxic-ischemic, and traumatic (Lyon et al, 2006).

our results were similar to that stated by Kaemingk et al.,(2004)who study two groups one ALL patients received only chemotherapy(including intrathecal methotrexate)and healthy control ,it was founded that there is mathematics difficulties in ALL group compared to control group ,this as seen in our study in significant quantitative difference between cases and control, as Quantitative IQ represents an individual's store of acquired mathematical knowledge( McGrew,2009). It is stated that mathematics is very sensitive to any change in white matter (McGrew, 2009). Our results were somewhat similar to that stated by Hassab et al., (2015) who reported that the IQ, specially the verbal subscale was significantly affected in patients(ALL) who received full course of chemotherapy including intrathecal methotrexate 
compared to controls, recently Kanellopoulos et al., (2017) concluded that the very long-term survivors of childhood ALL treated exclusively with chemotherapy including intrathecal methotrexate showed no impairment in general intellectual ability, but significantly poorer performance in several neurocognitive domains including processing speed (color naming and word reading), executing functions, verbal learning and memory.

In the study stated by Carey et al.,(2016), there are lower mean score of attention, visual construction, mental flexibility, vocabulary and math achievement in ALL group received intrathecal methotrexate in comparison this as seen in our study

In significant quantitative and verbal difference between cases and control, Carey et al.,(2016) found that a significant relationship between white matter volume in the region of the right middle frontal gyrus and Tests of Achievement Calculation, with decreased volume associated with decreased math performance, also it is revealed a significant relationship between white matter volume in the region of the right superior frontal gyrus and Vocabulary, with decreased volume associated with decreased performance.

Iuvone et al., (2002), Anderson et al., (2000) and Langer et al., (2002) showed a greater neurotoxic effect of chemotherapy or cranial radiation or both when given to the younger patient as white matter development continues up to $\mathbf{2 0}$ years this explain our results as significant difference in verbal subscale was found between younger and older age groups among studied cases.
Therefore, those who are younger at treatment generally have less fully developed white matter so as early beginning intrathecal treatment as more white matter loss as more neurocognitive function defects. However, since both younger and older patients have been shown to lose white matter at similar rates (Reddick et al., 2000), the younger irradiated patients or who received intrathecal chemotherapy continue to display reduced total white matter volume following either treatment. These deficits in white matter volume among younger patients have also been associated with increased intellectual morbidity (Mulhern et al., 2001).

There is excellent outcome for most forms of childhood and adolescent NHL Patients with localized disease have a 90-100\% chance of survival, and those with advanced disease have a $\mathbf{7 0 - 9 5 \%}$ chance of survival. As outcomes for pediatric patients with NHL have improved substantially, the focus has now shifted to minimizing the long-term toxicity of therapy (lanzkowskey et al, 2016).

In a study named Disease patterns of pediatric non-Hodgkin lymphoma: A study from a developing area in Egypt at the Pediatric Oncology Unit of Zagazig University Hospital and the Benha Specialized Pediatric Hospital, it is founded Complete remission was achieved in $(\mathbf{8 4 . 5 \%}),(\mathbf{1 1 . 3 \%})$ of them succumbed to the disease (relapse) during the first few months and $\mathbf{( 4 . 2 \% )}$ ) remained alive following relapse. The mean followup duration \pm SD was 34.6 $\pm \mathbf{2 5 . 1}$ months .The 5-year overall survival (OS) and event-free survival (EFS) rates were $\mathbf{8 8 . 7}$ and $85.1 \%$, respectively (LAILA $M$. SHERIEF et al, 2015). 


\section{Summary}

Methotrexate has harmful adverse effect on congnitive functions of children treated for NHL (in verbal and quantitative subscales), and this effect increases when MTX treatment started at younger age.

\section{References}

1. Anderson VA, Godber T, Smibert E, Weiskop S, Ekert H (2000). Cognitive and academic outcome following cranial irradiation and chemotherapy in children: a longitudinal study. Br J Cancer 82:25562.

2. Anderson, John $R$ (2004). Cognitive psychology and its implications $\left(6^{\text {th }}\right.$ ed.). Worth Publishers. 519. ISBN 978-07167-0110-1.

3. Buizer AI, de Sonneville LM, Veerman A (2009). Effects of chemotherapy on neurocognitive function in children with acute lymphoblastic leukemia: A critical review of the literature. Pediatr Blood Cancer 52:447-54.

4. Cairo MS (2009). Non-Hodgkin's Lymphoma and Lymphoproliferative Disorders in Children. In: Carroll WL, FinlayJL, eds. Cancer in Children and Adolescents. Jones \& Bartlett Publishers, available online.

5. Carey ME, Haut MW, Reminger SL (2008). Reduced frontal white matter volume in long term childhood leukemia survivor: A voxel-based morphology study. Am J Neurological 29:792-797.

6. Gangjee A, Jain HD, Kurup S (2007). Recent advances in classical and non-classical antifolates as antitumor and antiopportunistic infection agents: part I. Anticancer Agents Med Chem 7(5):52442.

7. Garcia-Puig M, Fons-Estupina $\underline{\mathrm{MC}}$, Rives-Sola S, Berrueco-Moreno $\underline{\mathrm{R}}$ Cruz-Martinez $\mathrm{O}$, Campistol J (2012). Neurotoxicity due to methotrexate in paediatric patients.
8. Description of the clinical symptoms and neuroimaging findings. Rev Neurol. 54(12):712-8.

9. Hassab HM, Azouz HG, Elsakka EE, Awwad HE (2015). Assessment of Cognitive Function in Children with Acute Lymphoblastic Leukemia. Annals of Clinical and Laboratory Research ISSN 2386-5180 (special issue):1-10.

10. Iuvone $L$, Mariotti $P$, Colosimo $C$, Guzzetta F, Ruggiero A (2002). Longterm cognitive outcome, brain computed tomography scan, and magnetic resonance imaging in children cured for acute lymphoblastic leukemia. Cancer 95:2562-70.

11. Iyer NS, Balsamo LM, Bracken MB, Kadan-Lottick NS (2015). Chemotherapy-only treatment effects on long-term neurocognitive functioning in childhood ALL survivors: a review and meta-analysis. Blood. 126(3):346-53.

12. Kadan-Lottick NS, Zeltzer LK, Liu Q (2017). The Behavior Rating Inventory of Executive Function (BRIEF) to Identify Pediatric Acute Lymphoblastic Leukemia (ALL) Survivors At Risk for Neurocognitive Impairment $\mathbf{J}$ Pediatr Hematol Oncol.. 102(12):881-93.

13. Kaemingk KL, Carey Me, Moore IM (2004). Math weakness in survivor of ALL compared to healthy children, Child Neuropsychol 10;14-23.

14. Kanellopoulos A, Andersson S, Zeller B, Tamnes CK, Fjell AM, Walhovd KB (2017). Neurocognitive Outcome in Very Long-Term Survivors of Childhood Acute Lymphoblastic Leukemia After Treatment with Chemotherapy Only. Pediatric blood \& cancer. 63(1):133-8.

15. LAILA M. SHERIEF, USAMA R. ELSAFY, ELHAMY R. ABDELKHALEK, NAGLAA M. KAMAL, DOAA M. YOUSSEF , RABAB ELBEHEDY (2015) Disease patterns of pediatric non-Hodgkin lymphoma: A study from a developing area in Egypt .Mol Clin Oncol. 2015 Jan; 3(1): 139-144. 
16. Langer $T$, Martus $P$, Ottensmeier H, Hertzberg H, Beck JD (2002). CNS late-effects after ALL therapy in childhood. Part III: neuropsychological performance in long-term survivors of childhood ALL: impairments of concentration, attention, and memory. Med Pediatr Oncol 38:320-8.

17. Lanzkowsky ,Jeffery Lipton and Jonathan Fish (2016); Evaluation, investigation and management of late effects of childhood cancer

18. Lyon G, Fattal-Valevski A, Kolodny EH (2006). Leukodystrophies: Topics in Magnetic Resonance Imaging. 17(4):219-42

19. Miller DR (2006). A tribute to Sidney Farber - the father of modern chemotherapy. British Journal of Haematology 134(1):20-6.
20. Mukherjee $\mathbf{S}$ (2010). The Emperor of All Maladies: A Biography of Cancer. Simon and Schuster. ISBN 978-1-43910795-9, available online.

21. Mulhern RK, Palmer SL, Reddick WE, Glass JO, Kun LE (2001). Risks of young age for selected neurocognitive deficits in medulloblastoma are associated with white matter loss. J Clin Oncol 19:472-9.

22. Reddick WE, Russell JM, Glass JO, Xiong X, Mulhern RK (2000). Subtle white matter volume differences in children treated for medulloblastoma with conventional or reduced dose craniospinal irradiation. Magn Reson Imaging 18:787-93. 